\title{
Non-compliance with guidelines on protonpump inhibitor prescription as gastroprotection in hospitalized surgical patients who are prescribed NSAIDs
}

Running head: PPI prescription in surgical NSAID users

Patricia M.L.A. van den Bemt, PharmD, $\mathrm{PhD}^{3}$, Naoual Chaaouit, BSc${ }^{2}$, Esther M.M. van Lieshout, $\mathrm{PhD}^{3}$, Michael H.J. Verhofstad, MD, $\mathrm{PhD}^{3}$

${ }^{1}$ Department of Hospital Pharmacy, Erasmus University Medical Center, Rotterdam, The Netherlands

2Utrecht University, Utrecht, The Netherlands

${ }^{3}$ Trauma Research Unit, Department of Surgery, Erasmus University Medical Center, Rotterdam, The Netherlands

\section{Corresponding author}

P.M.L.A. van den Bemt

Erasmus MC

Dpt. Hospital Pharmacy

P.O. Box 2040

3000 CA Rotterdam

e-mail p.vandenbemt@erasmusmc.nl

tel. +31107033202

fax +31107032400 
Conflicts of Interest and Source of Funding

None declared. 


\section{Structured Abstract}

\section{Background and aims}

Since nonsteroidal anti-inflammatory drugs (NSAIDs) can cause serious upper gastrointestinal (GI) harm, guidelines have been established for the prescribing of proton pump inhibitors (PPIs) in high risk patients using NSAIDs. Studies looking into guideline compliance in surgical patients are scarce. Therefore, a retrospective cross-sectional database study was performed aimed at determining the proportion of non-compliance with the Dutch guideline, and at determining the association of several factors with this non-compliance.

\section{Materials and methods}

Included were hospital admissions of patients on surgical wards of Erasmus MC between January 1, 2013, to August 1, 2014 in which an NSAID was newly prescribed. Excluded was pre-admission PPI use. The main outcome was the proportion of non-compliance with the guideline. As a secondary outcome the association of several potential risk factors with noncompliance was assessed. The proportion of guideline non-compliance was calculated as percentage of all included surgical ward admissions. For the secondary analysis, univariate and multivariable logistic regression analysis was performed.

\section{Results}

Fourhundred-and-nine admissions were included. The proportion of admissions in which guideline non-compliance was present was $46.6 \%$, mostly due to incorrectly added PPIs. Coxib 
use (adjusted OR 0.22 (95\% confidence interval 0.12-0.44), polypharmacy (the use of 5 or more drugs) (2.18 (1.27-3.76)) and the surgical wards orthopedics (22.32 (5.38-92.55)), plastic surgery (10.82 (2.51-46.59)), trauma surgery (5.78 (1.47-22.70)), and transplant/vascular surgery (4.45 (1.10-18.00)), were statistically significantly associated with non-compliance.

\section{Conclusion}

Non-compliance with the guideline on NSAID use and gastroprotection is present in almost half of surgical hospital admissions and mainly concerns overprescribing.

\section{Keywords}

NSAID, gastroprotection, PPI, guideline non-compliance 


\section{Introduction}

Non-Steroidal Anti-Inflammatory Drugs (NSAIDs) are widely used for their analgesic, antipyretic, and anti-inflammatory effects ${ }^{[1,2]}$.Upper gastrointestinal events with clinical symptoms occur in $2.5-4.5 \%$ of patients and these are serious in approximately $1.0-1.5 \%$ of patients ${ }^{[3]}$. As the costs associated with these events are substantial, prevention by using gastroprotective strategies may be cost-effective, especially in high risk patients ${ }^{[4]}$. Therefore, guidelines have been implemented for the prescription of gastroprotective strategies in high risk patients. In the Netherlands the guideline 'NSAID-use and prevention of gastric toxicity' of the Dutch Institute for Health Care Improvement from $2003^{[5]}$ and the HARM-wrestling recommendations from 2009[6] are the evidence based guidelines most broadly used. HARM stands for Hospital Admissions Related to Medication; the HARM-wrestling recommendations were based on the results of the HARM study[7].

Both guidelines recommend a gastroprotective strategy in high risk patients (see table 1 for the recommendations in the guidelines).Comparable guidelines are published in other countries, but they are not always complied to. In the Netherlands, Sturkenboom et al. showed already in 2003 that gastroprotective strategies were underused in patients on NSAIDs ${ }^{[8]}$. A very recent study showed that gastroprotection use had increased in time, but that there was still room for improvement ${ }^{[9]}$. These Dutch studies are confirmed by a large US study, also showing underuse of gastroprotection ${ }^{[10]}$. Another US study showed that reimbursement of medication plays an important role in underuse of gastroprotection ${ }^{[11]}$.

Besides underutilization of gastroprotective agents, overuse is also common especially within hospitals $^{[12,13]}$. Increasingly, studies on adverse drug reactions caused by PPIs are being published, contradicting the overall professional opinion regarding the high safety of this drug class. Hypomagnesemia ${ }^{[14]}$, increased fracture risk ${ }^{[15]}$, hypovitaminosis $B 12^{[16]}$, and community 
acquired pneumonia[17] have all been linked to PPI use, although the evidence is rarely conclusive. Given these reports, it becomes increasingly important to only use PPIs when indicated. In hospitals NSAIDs are often initiated as postoperative analgesics and PPIs are costarted as gastroprotective agents which may result in chronic PPI use: after the NSAID is stopped, the PPI is continued inadvertently ${ }^{[12]}$. This makes it all the more important to only add PPIs when strictly indicated. Therefore, we performed a study aimed to determine the noncompliance with guidelines for prescribing PPIs as gastroprotective agents in NSAID users in surgical patients. Secondary aim was to determine risk factors associated with guideline noncompliance.

\section{Methods}

\section{Study design}

A single-center retrospective database study was conducted using data from the electronic patient record (Elpado, non-commercial homegrown system) of the Erasmus University Medical Center (Erasmus MC) in Rotterdam, the Netherlands. All data were handled confidentially. Patient and prescriber identification lists were made and the data were stored in a database in a coded way, not to be tracked back to the specific patient or prescriber. The study was conducted according to the Personal Data Protection Act. The Medical Research Ethics Committee (MREC) of Erasmus MC provided a waiver for the study.

\section{Study population}

The study base population comprised all hospital admissions of patients admitted to the surgical wards of Erasmus MC from January 1, 2013, to July 31, 2014 in which the patient received a 
nsNSAID (ATC code M01AB, M01AC, M01AE or coxib (ATC code M01AH)

(http://www.whocc.no/atc ddd index/; accessed August 2015). From this base population a sample of hospital admissions was selected by including each 10 th patient, with equal selection of all surgical wards. After reaching the end of the dataset, again every 10th patient of the remaining patients was selected, and so on. Each selected patient was first checked for the following inclusion and exclusion criteria.

Inclusion criteria for admitted patients were 18 years and older of age and starting an NSAID while in hospital. Exclusion criteria were pre-hospital NSAID use continued during hospitalization, pre-hospital PPI use continued during hospitalization, or a combination of both, PPI prescription at least two hours prior to NSAID prescription in hospital, and dermal NSAID use.

The selection was repeated until 250 eligible hospital admissions were included (see Data analysis for sample size collection).

\section{Data collection}

Eligible patients were selected from the computerized physician order entry system (Medicator ${ }^{\circledR}$, CSC-Isoft, Leiden, The Netherlands), based on the use of nsNSAIDs or coxibs. General patient and medical data were collected from the electronic patient records: gender, date of birth, date of hospital admission, date of hospital discharge, the physician who prescribed the NSAID (coded by a number), name of surgical ward, name of NSAID, start date of NSAID prescription, stop date of NSAID prescription, daily NSAID dose, NSAID prescribed 'as needed' or not, number of medicines coprescribed with NSAID (NSAID included in counting), whether the patient had a history of a PUOB or not, whether the patient had a history of untreated $\mathrm{H}$. pylori infection or not, relevant co-morbidities (rheumatoid arthritis, diabetes mellitus, cardiac failure) 
and how many if applicable, risk medication (according to guideline) present or not and how many and which class of risk medication if applicable, PPI use or not, start date and stop date of PPI use if applicable.

We decided not to include comedication with non-oral anticoagulants or with spironolacton as risk medication, because neither were included in the alert system of Medicator, which is based on the national G-standard, a system of drug-drug interaction alerts. So, although spironolacton is mentioned in the guidelines as high-risk medication, the Dutch medication surveillance systems based on the G-standard do not alert for this medication.

High-risk NSAID users and compliance with guideline on NSAID use and PPI prescription High-risk patients were defined according to the guideline of the Dutch Institute for Health Care Improvement and the HARM-wrestling report ${ }^{[6,7]}$. PPIs were assessed as needed when (a) the patient is 70 years of age or older, or has a history of gastric ulcer disease, or is infected with $\mathrm{H}$. pylori or (b) the patient is between $60-70$ years of age and has additional risk factors as described in the guidelines. Long term use of high dosages of NSAIDs was not applicable to our population, as the NSAIDs were mainly prescribed as postoperative analgesic.

Non-compliance with the guideline was defined as PPI prescription when the patient was not at risk for gastrointestinal toxicity according to the guidelines, or PPI prescription when the patient was at risk for gastrointestinal toxicity but received a coxib (without aspirin as comedication), or no PPI prescription when the patient was at risk for gastrointestinal toxicity according to the guidelines.

The appropriateness of coxib prescription (without a PPI) was not assessed in this study. 


\section{Outcome}

The primary outcome was non-compliance with PPI prescribing as mentioned in the national evidence-based guidelines on NSAID use and gastroprotection. The secondary outcome was the association of several potential risk factors with non-compliance with the guideline. These potential risk factors were based on the risk factors from the guidelines (e.g. age) combined with some general risk factors for prescribing errors (e.g. polypharmacy): age at day of hospital admission (classified into subgroups according to the guidelines' description of high-risk patients: below 60 years, 60-69 years and 70 years and older) and gender of the patient, surgical ward, type of NSAID (nsNSAID or coxib), polypharmacy defined as the use of five or more drugs concomitantly, duration of NSAID use, NSAID use as needed, history of an ulcer, number of relevant comorbidities, and the use of risk medication.

\section{Data monitoring}

A sample of $10 \%$ of the entered data in this form was checked for completeness and plausibility and for linkage to really existing patients by another person than the one entering it. Any systematic errors discovered in this sample were checked in the complete dataset and corrected where necessary. The complete dataset was also checked for outlier data and their validity was checked as well.

\section{Data analysis}

Data analysis was performed using IBM SPSS Statistics version 21. 
For the sample size, at least 10 cases of guideline non-compliance are required per studied potential risk factor. Thus we needed 100 cases for evaluating 10 potential risk factors. With an expected non-compliance rate of $40 \% 250$ hospital admissions were needed.

For the analysis of the primary outcome, the proportion of non-compliance with the guideline was calculated by dividing the number of hospital admissions with non-compliance by the total number of included admissions and expressed as the percentage of all included admissions. Also proportions for each type of non-compliance were calculated, namely PPI incorrectly added and PPI incorrectly not added. In addition, for the secondary analysis in this study, univariate and multivariable logistic regression analysis was performed. Potential risk factors with a statistically significant association in the univariate analysis, were entered into the multivariate model. When this changed the beta coefficient for at least $10 \%$, the risk factor was retained in the model. Unadjusted and adjusted odds ratios ( $O R$ and $\left.\mathrm{OR}_{\mathrm{adj}}\right)$ and their $95 \%$ confidence intervals $(95 \% \mathrm{Cls})$ were calculated.

\section{Results}

The study base population consisted of 3181 hospital admissions. A random subset of 480 hospital admissions was selected for screening of inclusion and exclusion criteria. In 231 hospital admissions, at least one reason for exclusion was present. Thus 249 hospital admissions of 248 patients (one patient was admitted twice during the study period) met the inclusion criteria (figure 1).

Table 2 shows the baseline patient characteristics of included hospital admissions. Mean age of the admitted patients was $43.5( \pm 17.7)$ years, with the majority of patients in the youngest age category ( $<60$ years). During most hospital admissions the nsNSAID diclofenac or the COX-2 selective NSAID etoricoxib were prescribed. In 48 (19.3\%) admissions, the patient received the 
NSAID as needed. No patients had a history of untreated infection with $\mathrm{H}$. pylori. The majority of patients did not have any comorbidities or risk medication. Diabetes mellitus was recorded in 10 (4.0\%) hospital admissions. In 19 (7.6\%) hospital admissions the receiving patient had risk medication together with the prescribed NSAID. In one $(0.4 \%)$ hospital admission the receiving patient had three of those medicines. There were no hospital admissions in which the patient had more than three of these medicines alongside the prescribed NSAID, nor hospital admissions in which the patient had more than one comorbidity.

\section{Guideline non-compliance}

In 116 hospital admissions non-compliance with the guideline on NSAID use and gastroprotection was identified, resulting in a proportion of $46.6 \%$. In 108 (43.4\% of all admissions; $93.1 \%$ of non-compliant admissions) admissions the PPI was incorrectly added and in 8 (3.2\% of all admissions; $6.9 \%$ of non-compliant admissions) the PPI was incorrectly not added.

\section{Potential risk factors for non-compliance}

Unadjusted odds ratios of the univariate analysis of the association between several potential risk factors and non-compliance, are presented in table 3. Coxib use was inversely associated with guideline non-compliance. Polypharmacy and surgical ward type were found to be statistically significant associated with non-compliance. The same table shows the results of the multivariable analysis, for those factors that were statistically significantly associated with noncompliance in the univariate analysis. 
Polypharmacy defined as the use of 5 or more drugs (OR 2.18 (1.27-3.76)) and the surgical wards orthopedics (OR 22.32 (5.38-92.55)), plastic surgery (OR 10.82 (2.51-46.59)), trauma surgery (OR 5.78 (1.47-22.70)), and transplant/vascular surgery (OR 4.45 (1.10-18.00)), were statistically significantly associated with non-compliance. Coxib use (adjusted OR 0.22 (95\% confidence interval $0.12-0.44$ ) was inversely associated with non-compliance in the multivariable analysis.

\section{Discussion}

This study shows that in almost half of the hospital admissions to surgical wards, PPI prescribing is not compliant with the national guidelines on NSAID use and gastroprotection. A significant inverse association of coxib use with guideline non-compliance was found in this study. This means that when a coxib is prescribed, physicians comply more with the guideline on NSAID use and gastroprotection. As coxibs form a gastroprotective strategy as such, PPIs are more often correctly not coprescribed. This study also showed that polypharmacy and specific surgical wards are associated with guideline non-compliance. With an increasing number of medicines, it may become more difficult for doctors to interpret the guideline correctly. Specific ward protocols and/or culture may explain the differences between wards. Especially, orthopedic and plastic surgery wards seem to perform less than other wards. Our study was not designed to clarify the reasons for this and studies in other hospitals are needed to confirm this finding. Nevertheless, the variation of guideline non-compliance between surgical ward types may be the focus for tailored interventions to improve compliance.

We are not aware of any other study reporting on compliance with guidelines on NSAID use and gastroprotection among patients admitted to surgical wards. However, compliance with guidelines for PPI prescriptions has been investigated in other settings ${ }^{[8-11,18]}$. These studies 
have shown that compliance is low and PPIs are generally underprescribed. In contrast, this study showed that PPIs are generally being overprescribed. Several studies have confirmed overprescribing of PPIs, as we have found in our study ${ }^{[12,13]}$. One of these studies has been performed (partly) in the same hospital as ours, but in another type of ward, namely pulmonary medicine ward ${ }^{[13]}$. On such a ward NSAIDs are not used for purely postoperative reasons, as is mainly the case on the surgical wards in our study. We hypothesize that the main reason for overprescription in our study is a gap in the knowledge of the national guidelines and local protocols in the surgically oriented doctors and nurses. This can result in an unfounded fear for gastric complications. As a consequence of the very high incidence of NSAID prescription in surgical wards, the accompanying gastroprotection may come too easily along with it ("it doesn't harm to try"). As most studies on gastrointestinal toxicity and risk factors involve patients on chronic NSAID therapy, the guidelines on gastroprotection are also based on such long term NSAID use. Little is known on the effect of gastroprotection in short term use of NSAIDs, making careful selection of PPI prescription even more important, especially since PPI's are often inadvertently continued even though the NSAID has been stopped.

The strengths of this study are the complete medication data that are available in the computerized physician order entry system, allowing accurate retrospective assessment of drug exposure. The use of the hospital database allowed the identification of all patients prescribed NSAIDs during the study period and assessment of individual patient and treatment characteristics that are important in determination of compliance.

Some potential limitations were present in this study. First, because of the retrospective design of this study, we could have missed essential data for the determination of compliance with the guidelines. Second, indications for the prescribed PPI were most of the time not recorded. It could be the case that the patient had other symptoms and the PPI was prescribed for another indication than as co-medication with an NSAID. Therefore, we may have overestimated the 
number of patients with non-compliance. However, we prevented this as much as possible, by excluding patients who received the PPI at least two hours before the NSAID. In addition, most PPI's were prescribed at exactly the same time as the NSAID, rendering an alternative indication more unlikely. Third, it was not always obvious whether the patient had the NSAID or PPI or both prescribed in hospital, or whether the patient had the medication already from home, adopted in hospital by the prescribing physician. This could have led to inclusion of patients who should actually have been excluded, and thus this could have led to an overestimated effect. However, determination of whether the medication was from home or not was carried out in a standardized manner. Also, as many resources as possible were used to determine whether the medication was from home, so we do not expect a major bias due to this. Finally, this study was carried out in a single center setting which may limit the generalizability of our results. However, we know that in many surgical wards not prescibing gastroprotection along a NSAD is more or less considered an omission. We thus plead for better teaching of surgical doctors and nurses.

In the current study, we did not investigate non-compliance with guidelines in a multicenter setting with larger numbers of patients; this is subject for future research. Another interesting topic for future research is the investigation of coxib prescribing compliance with guidelines. Finally, additional research is necessary on interventions aimed at improving guideline compliance.

In conclusion, non-compliance with the national evidence-based guideline on NSAID use and PPI prescription as gastroprotection is high, mostly because PPIs are being overprescribed. Improvement is necessary and could be focused on the risk factors identified in this study. Such improvements may lead to substantial cost-savings and the prevention of PPI related toxicity. 


\section{References}

1. Laine L. Approaches to nonsteroidal anti-inflammatory drug use in the high-risk patient. Gastroenterol 2001;120:594-606.

2. Inotai A, Hankó B, Mészáros A. Trends in the non-steroidal anti-inflammatory drug market in six Central-Eastern European countries based on retail information. Pharmacoepid Drug Saf 2010;19:183-190.

3. Laine L. GI risk and risk factors of NSAIDs. J Cardiovasc Pharmacol 2006;47(suppl.1):S60S66.

4. Vonkeman HE, Braakman-Jansen LMA, Klok RM, Postma MJ, Brouwers JRBJ, Van de Laar MAFJ. Incremental cost effectiveness of proton pump inhibitors for the prevention of nonsteroidal anti-inflammatory drug ulcers: a pharmacoeconomic analysis linked to a casecontrol study. Arthr Res Ther 2008;10:R144.

5. The Dutch Institute for Health Care improvement CBO. Guideline NSAID use and prevention of gastric damage. [Richtlijn NSAID-gebruik en preventie van maagschade]. The Dutch Institute for Health Care Improvement CBO: Utrecht, 2003. Available at http://www.mdl.nl/uploads/240/117/NSAID-gebruik_en_preventie_van_maagschade__CBO_2003.pdf (accessed on 08/18/2015).

6. Warlé-Van Herwaarden MF, Kramers C, Sturkenboom MC, Van den Bemt PM, De Smet PA. Targeting outpatient drug safety: recommendations of the Dutch Harm-Wrestling Task Force. [HARM-WRESTLING: een voorstel van de Expertgroep Medicatieveiligheid m.b.t. concrete interventies die de extramurale medicatieveiligheid op korte termijn kunnen verbeteren]. Ministry of Health, Welfare and Sport: Den Haag, 2009. Available at http://www.knmp.nl/downloads/medicijnenzorgverlening/medicatieveiligheid/harmwrestlingrapportdefnov2009.pdf (accessed on 08/18/2015) 
7. Leendertse AJ, Egberts ACG, Stoker LJ, van den Bemt PMLA; for the HARM study group. Frequency of and risk factors for preventable medication-related hospital admissions in the Netherlands. Arch Intern Med 2008;168:1890-96.

8. Sturkenboom MCJM, Burke TA, Dieleman JP, Tangelder MJD, Lee F, Goldstein JL. Underutilization of preventive strategies in patiens receiving NSAIDs. Rheumatol 2003;42(suppl3):iii23-iii31.

9. Warlé-Van Herwaarden MF, Koffeman AR, Valkhoff VE, 't Jong GW, Kramers C, Sturkenboom MC et al. Time-trends in the prescribing of gastroprotective agents to primary care patients initiating low-dose aspirin or non-steroidal anti-inflammatory drugs: a population-based cohort study. Br J Clin Pharmacol 2015;80:589-598.

10. Abraham NS, El-Serag HB, Johnson ML, Richardson P, Ray WA, Smalley W. National adherence to evidence-based guidelines for the prescription of nonsteroidal antiinflammatory drugs. Gastroenterol 2005;129:1171-1178.

11. Marcum ZA, Hanlon JT, Strotmeyer ES, Newman AB, Shorr RI, Simonsick EM et al, for the Health, Aging and Body Composition Study. Gastroprotective agent underuse in high-risk older daily nonsteroidal anti-inflammatory drug users over time. J Am Geriatr Soc 2014;62:1923-1927.

12. Eid SM, Boueiz A, Paranji S, Mativo C, Landis R, Abougergi MS. Patterns and predictors of proton pump inhibitor overuse among academic and non-academic hospitalists. Intern Med 2010;49:2561-2568.

13. Van Vliet EPM, Otten HJAM, Rudolphus A, Knoester PD, Hoogsteden HC, Kuipers EJ et al. Inappropriate prescription of proton pump inhibitors on two pulmonary medicine wards. Eur J Gastroenterol Hepatol 2008;20:608-612.

14. Famularo G, Gasbarrone L, Minisola G. Hypomagnesemia and proton-pump inhibitors. Exp Opin Drug Saf 2013;12:709-716. 
15. Yu EW, Bauer SR, Bain PA, Bauer DC. Proton pump inhibitors and risk of fractures: a metaanalysis of 11 international studies. Am J Med 2011;124:519-526.

16. Lam JR, Schneider JL, Zhao W, Corley DA. Proton pump inhibitor and histamine 2 receptor antagonist use and vitamin B12 deficiency. JAMA 2013;310:2435-2442.

17. Filion KB, Chateau D, Targownik LE, Gershon A, Durand M, Tamim H et al, the CNODES Investigators. Proton pump inhibitors and the risk of hospitalization for community-acquired pneumonia: replicated cohort studies with meta-analysis. Gut 2014;63:552-558.

18. Valkhoff VE, van Soest EM, Sturkenboom MCJM, Kuipers EJ. Time-trends in gastroprotection with nonsteroidal anti-inflammatory drugs (NSAIDs). Alim Pharmacol Ther 2010;31:1218-1228. 

Table 1. Recormmendations in the guideine of the Dutch Irstitute for Heathcare Improvement and in the HARM-wresting report

\begin{tabular}{|c|c|}
\hline Add gastroprotaction & \\
\hline Nways in & $\begin{array}{l}\text { Pafients agod } 70 \text { yours and older } \\
\text { Pafents with sorious gastro intesfinal events } \\
\text { in thair modical history } \\
\text { Pafents who tost positive for Halicabactar } \\
\text { pybin }\end{array}$ \\
\hline $\begin{array}{l}\text { In pofients aged } 60-70 \text { yours, } \\
\text { only when }\end{array}$ & Use of highriek oomedication \\
\hline & Systomic oortoostorcids \\
\hline & Soloctive sorotonin rouptale inhbitors \\
\hline & $\begin{array}{l}\text { Vitamin } K \text { antagonists or other } \\
\text { antioosguhnts }\end{array}$ \\
\hline & Aspin \\
\hline & Spironohctone" \\
\hline & High riek comoridity \\
\hline & Phoumatoid arthrits \\
\hline & Diabetos mellitus \\
\hline & Cardino faiure \\
\hline & Using long-torm or high dosages of NSNDs \\
\hline Comparabie gastroprotoctive s & \\
\hline & $\begin{array}{l}\text { Addition of PPI to nonselective NSAD } \\
\text { Addition of high-does } \mathrm{H} 2 \text { antagonist to } \\
\text { nonseloctive NSAID }\end{array}$ \\
\hline & $\begin{array}{l}\text { Addition of misoprostdi to nonseloctive } \\
\text { NSWD }^{b}\end{array}$ \\
\hline & Use of solective NSND (ocoib) \\
\hline
\end{tabular}

PPL, proton pump inhibitor:

Mnly mentionod in HARM-wrosing report

Bocsuse of adverse drug rasctions, nonproforable statogios.

"Exoept whon aspirin in comodication; aspirin roduces the gastroprotective effoct

of coxibe. 


\begin{tabular}{|c|c|}
\hline \multicolumn{2}{|l|}{ Pafents } \\
\hline Age (masn $\pm S D$ ) fraors) & $435 \pm 127$ \\
\hline$<60$ hn $(96)]$ & $197(79.1)$ \\
\hline $60-69 \ln (\% 6)]$ & $31(124)$ \\
\hline$\geq 70[n[96)]$ & $21(8.4)$ \\
\hline Mab $\sec [n(96)]$ & $136(54.6)$ \\
\hline Mean durition of hopital stay (man 1 SD) (days) & $7.3 \pm 10.5$ \\
\hline \multicolumn{2}{|l|}{ Surgical ward $[n(96)]$} \\
\hline Genoral surgary & $18(7.2)$ \\
\hline Nourosurgery & 17 (B. 19 \\
\hline Otthapodios & 47 (189) \\
\hline Truma surgory & 45 (18.1) \\
\hline Otorhindaryngology & $42(169)$ \\
\hline Eye surgery & $13(5.2)$ \\
\hline Plastic angary & $29(11 B)$ \\
\hline Transplant and vesouhr surgery & $39(15.3)$ \\
\hline \multicolumn{2}{|l|}{ Modication [n (96)] } \\
\hline Caxb & $119(428)$ \\
\hline Etoriooxb & $102(410)$ \\
\hline Calocaxb & 17 (8.9) \\
\hline nSNSAID & $130(522)$ \\
\hline Dicblonso & $118(424)$ \\
\hline lbuprodon & $6(2.4)$ \\
\hline Indome tacin & $5(2.0)$ \\
\hline Napraxan & 10.40 \\
\hline Mean duration of NSAID use (masn 1 SD) (days) & $3.4 \pm 6.4$ \\
\hline NSND as nooded [n (\%6)] & $48(193)$ \\
\hline $\mathrm{PPI}$ prescription $[n(\%)]$ & $119(4 \mathrm{zg})$ \\
\hline Mesn number of comodications (masn $\pm S D$ ) & $6.5 \pm 3.2$ \\
\hline \multicolumn{2}{|l|}{ Risk factors [n (96)] } \\
\hline $\begin{array}{l}\text { Hetory of uloor } \\
\text { Comorbidtes }[\mathrm{n}(96)]\end{array}$ & $4(1.6)$ \\
\hline No mberent & $230(92,4)$ \\
\hline Rhoumatrid arthinis & $6(2.4)$ \\
\hline Dabetes malius & $10(4.0)$ \\
\hline & $3(1.2)$ \\
\hline \multicolumn{2}{|l|}{ Presk medication $[n(\%)]$} \\
\hline None & $230(92.4)$ \\
\hline Ond antioosglant & 210.80 \\
\hline SSRI & $6(2.4)$ \\
\hline Cotionstaraid & $6(2.4)$ \\
\hline Aspin & 72.80 \\
\hline
\end{tabular}

neNSND, nanseloctive NSAD; PPL, proton pump intibitor; SSRI, soctive sor. otonin muptake inhbitors. 
Table 3. Associaton of potentia risk factors with guideline

noncompliance

\begin{tabular}{|c|c|c|}
\hline Age (years) & OR (95\% CA) & $O R_{a 4}(96 \% \mathrm{C})$ \\
\hline$<60$ & Reot. & \\
\hline $60-69$ & $0.71(0.33-1.53)$ & \\
\hline$\geq 20$ & $1.23(0.50-3.03)$ & \\
\hline \multicolumn{3}{|l|}{$\operatorname{Sex}$} \\
\hline Malo & Rot. & \\
\hline Fomal & $1.02(0.62-1.69)$ & \\
\hline \multicolumn{3}{|l|}{ Surgical ward } \\
\hline Gononl surgary & Rot. & Ref. \\
\hline Nouroaugary & $0.75(0.14-3.99)$ & $2.02(0.34-12.17)^{A}$ \\
\hline Orthopedios & 10.21 (281-3209) & $22.32(5.38-92.55)^{4}$ \\
\hline Trauma surgory & $3.08(0.87-10.75)$ & $5.78(1.47-22.70)^{A}$ \\
\hline Ototinindaryngology & $1.94(0.54-6.909)$ & $270(0.69-10.83)^{\circ}$ \\
\hline Eyo surgery & $1.56(0.31-285)$ & $1.25(0.23-6.78)^{4}$ \\
\hline Phastio surgory & $6.65(1.73-25.64)$ & $10.82(251-46.59)^{n}$ \\
\hline Transphnt and vaxular suggery & $2.28(0.83-8.27)$ & $4.45(1.10-1800)^{*}$ \\
\hline \multicolumn{3}{|l|}{ Polyphamacy } \\
\hline 5 or bss modicines & Rot. & Reft \\
\hline$>5$ medicinos & $1.71(1.03-2.84)$ & $2.18(1.27-3.76)^{b}$ \\
\hline \multicolumn{3}{|l|}{ Type of NSAD } \\
\hline nsNSND & Rot. & Ref. \\
\hline Cacib & $0.44(0.27-0.34)$ & $0.22(0.12-0.44)^{a}$ \\
\hline Duration of NSND uso & $0.98(0.94-1.03)$ & \\
\hline \multicolumn{3}{|l|}{ NSAD as nooded } \\
\hline Not as nooded & Rot & \\
\hline As nooded & $0.78(0.41-1.49)$ & \\
\hline \multicolumn{3}{|l|}{ History of an uloer } \\
\hline No & Rot. & \\
\hline Yos & $1.15(0.16-8.29)$ & \\
\hline \multicolumn{3}{|l|}{ Comorbodty } \\
\hline $\mathrm{No}$ & Rot. & \\
\hline Yos & $0.82(0.32-2.12)$ & \\
\hline \multicolumn{3}{|l|}{ Rick modication } \\
\hline $\mathrm{No}$ & Rot & \\
\hline Yos & $0.85(0.25-1.70)$ & \\
\hline
\end{tabular}

Cl confidenoe intorvel; nNSND, nonselective NSND; OR al adjustod odda rafio;

$\mathrm{OR}$, odda rafio; Rot, reforence catogory.

"Adustad for type of NSND and polypharmsoy.

"Adusted for type of NSND.

"Adustad for suggical ward and polypharmacy. 
Figure 1: Study flow

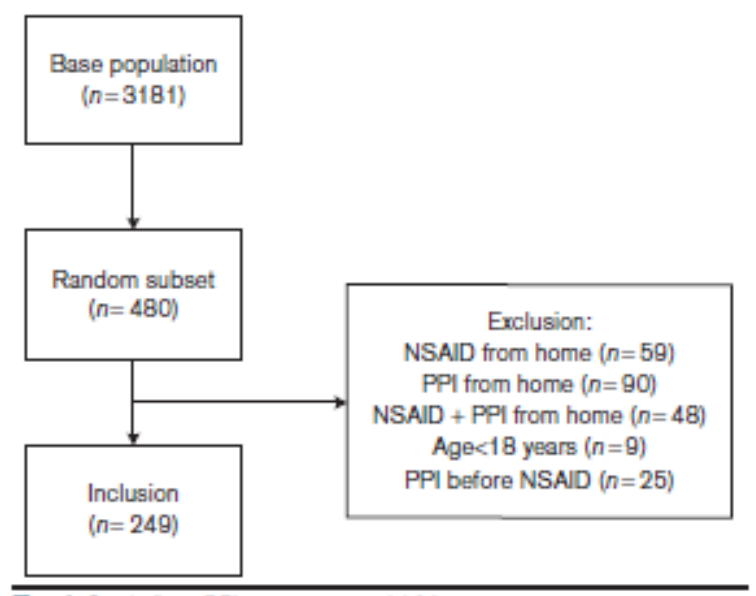

Fig. 1. Study flow. PP, proton pump inhbilor. 